\title{
Material Didático Para Incursões Locais: Ampliando Possibilidades Para a Geo- grafia Escolar Com o Atlas Municipal
}

\section{Educational Material for Incursions Local: Enlarging Possibilities for the School Geography With the Atlas Municipal}

\author{
Ana Isabel Leite Oliveira * \\ Eliany Dionizio Lima ** \\ Karla Maria de Queiroz dos Santos *** \\ Rute Araújo da Silva ***
}

\section{Resumo:}

Diante da execução do projeto de extensão "Laboratório SIG: atlas escolar", o objetivo deste trabalho é apresentar um relato da experiência referente a elaboração do atlas escolar para o município de Serrinha-BA, desenvolvido no curso de Licenciatura em Geografia do Campus XI, da Universidade do Estado da Bahia. De natureza exploratória-descritiva e caracterizado como pesquisa-ação, também se voltou para a formação de professores, ao propiciar a aprendizagem, a pesquisa, o fazer pedagógico e a utilização das tecnologias computacionais e geográficas para a produção de material didático com conteúdo local, primando pela inovação metodológica na prática de ensino.

\section{Abstract:}

In the face of the execution of the extension project "SIG Laboratory: School Atlas", the objective of this work is to present an account of the experience regarding the elaboration of the school atlas for the municipality of Serrinha-BA, developed in the course of Degree in Geography of Campus XI, Of the State University of Bahia. Exploratory-descriptive and characterized as action research, it also turned to teacher training, by providing learning, research, pedagogic and the use of computational and geographic technologies for the production of didactic material with local content, Focusing on methodological innovation in teaching practice.

* MSc. em Modelagem em Ciências da Terra e do Ambiente. Professora do curso de Geografia da UNEB do Campus XI - Serrinha.

** MSc. em Geografia pela UFS. Grupo de Pesquisa Estado, Capital, Trabalho e as Políticas de Re-ordenamentos Territoriais.

*** Graduanda em Geografia pela UNEB

Palavras-chave:

Atlas,

Lugar,

Ensino,

Geografia.

Key-Words:

Atlas,

Place,

Education,

Geography. 


\section{INTRODUÇÃO}

$\mathrm{O}$ s materiais didáticos são um importante recurso no processo de ensino-aprendizagem. Especialmente no ensino de Geografia, dispomos dos Atlas como obras de apoio fundamental. De acordo com Gonçalves (2009), a produção de Atlas Escolares Municipais tem crescido na última década, em decorrência da relevância que o lugar tem adquirido frente à necessidade de compreensão das "contrariedades e complexidades" do espaço geográfico.

A utilização dos atlas municipais pode evidenciar as intensas transformações que ocorrem no espaço físico e social, sendo que o lugar se coloca como categoria chave neste processo, pois o que está próximo pode ser melhor compreendido e relacionado a outras realidades não vivenciadas diretamente pelos sujeitos. Como bem destaca Santos (1997), o global se reflete no local e ambos encontram-se interligados, mas o local se diferencia em dinâmica e estrutura, apresenta particularidades, nele se expressam as relações que organizam fixos e fluxos.

Assim, é indispensável à disciplina Geografia a articulação do conteúdo programático com aspectos que possibilitem uma construção significativa do conhecimento, o que se pode concretizar na apropriação da categoria lugar no processo de ensino-aprendizagem. Entretanto, os materiais didáticos dificilmente apresentam recursos capazes de proporcionar essa abordagem, seja pelo contexto no qual são elaborados, seja pelas limitações impostas por questões relacionadas a custos e possibilidades de produção e publicação de conhecimento local. Torna-se, assim, um desafio para os profissionais da educação inserir de forma sistematizada conteúdos do cotidiano nas atividades escolares, ultrapassando a exploração dos conhecimentos prévios dos estudantes e da sua própria experiência.

Embora ganhe tal relevância, mesmo nas diretrizes nacionais da educação, Gonçalves (2009) destaca que materiais didáticos com conteúdos locais são raríssimos, influenciados, sobretudo, pelos limites de editoração. Isto concorre para a necessidade de elaboração deste tipo de recurso didático, destacando-se dentre eles o Atlas Escolar Municipal, que ao apresentar os elementos em grande escala oferece melhores possibilidades de compreensão da produção do espaço geográfico.

Gonçalves (2009) assevera, ainda, que há um ganho no desenvolvimento metodológico e na formação de professores quando ocorre a elaboração do Atlas Escolar pela relação estabelecida entre a academia e as escolas do ensino básico. O Atlas, geralmente produzido por cartógrafos e geógrafos, precisa atender às especificidades técnicas, ao rigor científico, mas também precisa estar adequado às necessidades reais da sala de aula.

Sua elaboração é um processo complexo. Em termos de apresentação, precisa reunir conhecimento, técnica e arte. A seleção do conteúdo deve atender à proposta pedagógica da série ou ciclo para o qual se destina. Além de manter qualidade científica, tanto textual como gráfica, e o apelo visual também não deve ser desconsiderado. Se impresso, coabitará com o fascínio e possibilidades de visualização interativa do mundo digital.

Pensado enquanto recurso didático, podemos refletir sobre um ensino que utilize o atlas não apenas como mais um material escolar, mas lance mão das possibilidades didáticas, tomando-o inclusive protagonista do processo de ensino-aprendizagem. Trata-se da incorporação de uma metodologia inovadora, na qual de coadjuvante o atlas passe igualmente a personagem principal. Sobretudo, se haurido localmente, pois um trajeto do conhecido para o imaginado torna mais significativa a aprendizagem, ou seja, do local para o regional e/ou global retornando para o local, transitando nas escalas geográficas.

Neste intento, fez-se a proposta de um projeto de extensão universitária, cujo objetivo geral recai sobre a elaboração de atlas escolares municipais, em um curso de licenciatura em Geografia. Compreende-se que este se constitui um material didático capaz de suprir parte da lacuna para condução de uma abordagem crítica e reflexiva a partir do lugar de vivência do aluno (ensino pelo atlas) e de oferecer recursos para a alfabetização (carto)gráfica (ensino do atlas), atendendo aos propósitos dos documentos oficiais que traçam as diretrizes para o ensino de Geografia.

Outras intenções recaem sobre o reforço na inserção das diversas linguagens no ensino de Geografia e formação de professores, através da valorização da linguagem gráfica como metodologia de ensino-aprendizagem, superando a visão restritiva que este recurso didático possa apresentar, assim como ser compreendido enquanto processo que busca conduzir os licenciandos em Geografia a refletirem e a desenvolverem novas estratégicas para prática docente.

Nos Parâmetros Curriculares Nacionais para o Ensino de Geografia no Ensino Fundamental, a Cartografia, por exemplo, figura como uma linguagem capaz de refletir sentidos culturais, estéticos, técnicos e históricos que os objetos expressam, suas interpretações, hipóteses e con- 
ceitos, colocam-se como referência para a leitura da paisagem, da espacialização dos elementos geográficos, o que pode ser expandido para o atlas municipal. Capacidades específicas de representação do espaço, leitura crítica da realidade vinculada ao espaço vivido são enfatizados neste documento norteador, assim como nesta proposta.

Diante da experiência de execução do projeto "Laboratório SIG: atlas escolar", neste artigo, nosso objetivo foi relatar o processo de elaboração de atlas escolar, com conteúdo local, voltado para o ensino de Geografia no terceiro ciclo do ensino fundamental para o município de Serrinha, no estado da Bahia. Para tanto, discorreremos sobre o papel dos materiais didáticos, com enfoque para o atlas escolar municipal; sobre a importância da aproximação dos conteúdos curriculares com o espaço de vivência do aluno nas aulas de Geografia; expondo em sequência a experiência de elaboração de atlas escolar para o referido município; e a indicação possibilidades e desafios na produção local de atlas escolares municipais para o ensino de Geografia.

Metodologicamente, o projeto estruturou-se numa ambitude exploratória-descritiva. Realizou-se análises empíricas e teóricas, com coleta, organização e interpretação de dados primários por meio de observação, e secundários em fontes institucionais e bibliográficas, tanto do tipo qualitativo como quantitativo. Caracterizou-se como uma pesquisa ação, compreendida enquanto processo que busca conduzir seus participantes a refletirem sobre a prática docente, bem como contribuir para a o desenvolvimento de habilidades para proposições de novos recursos didáticos.

\section{ATLAS ESCOLAR MUNICIPAL: MATERIAL DIDÁTICO E METODOLOGIA DE ENSINO}

Pensar em metodologias inovadoras para o ensino de Geografia é uma inciativa complexa. Nesta perspectiva, é necessário definir o que se entende por "inovador", sendo que tal aspecto recai na imperativa formação docente com forte fundamento teórico-metodológico.

Souza et al (2014), tratando das complexas transformações da sociedade contemporânea, advindas do acúmulo de conhecimento e avanços tecnológicos, consideram metodologia inovadora como "uma prática pedagógica ética, crítica, reflexiva e transformadora, ultrapassando os limites do treinamento puramente técnico, para efetivamente alcançar a formação" (p. 285). Nesta perspectiva, a inovação no processo educativo visa superar a memorização de conteúdos e o seu depósito na mente dos educandos, incorporando discen- tes e docentes como sujeitos, relacionando teoria e prática, o que não ocorre desvinculado do seu espaço de vivência e da sua relação com as demais escalas geográficas.

Também Castellar (2011), apropria-se do conceito de metodologia inovadora para designar processo e conteúdo como unidade, diante da complexidade contemporânea. Isto induz a imersão dos sujeitos, docentes e discentes, no processo de ensino-aprendizagem, ao considerar a bagagem de aprendizado acumulada pelos alunos e a potencialização de atividades didáticas pela articulação entre teoria e prática. Para tanto, a autora destaca a importância da linguagem cartográfica pela concreticidade que ela atribui ao espaço real.

Podemos nos arriscar a afirmar que metodologia inovadora não é metodologia inédita, mas sim, procedimentos que explorem novas potencialidades e interesses no âmbito escolar. Neste aspecto, os atlas municipais podem figurar como uma proposta metodológica inovadora para o ensino de Geografia, auxiliando o desenvolvimento de habilidades em dimensões espaciais, criativa, interpretativas, tecnológica, didática, tanto para quem o elabora quanto para quem o utiliza.

Os professores de Geografia em suas aulas, geralmente utilizam atlas que abordam realidades mais gerais, por haver maior acesso ao material (carto)gráfico em escalas menores, estando também estas representações mais comumente presentes nos livros didáticos. Assim, a transposição da teoria para a compreensão da configuração geoespacial próxima apresenta limitações, pelo fato de dificilmente haver recursos que retratem a realidade local para fim escolar. Comumente, a disponibilidade de materiais didáticos para subsidiar o trabalho do professor no estudo local é mínima. Neste contexto, o atlas escolar municipal constitui-se um recurso, agora sim, inédito para o processo de ensino e aprendizagem potencialmente inovador.

Considerando as especificidades do atlas escolar municipal, é importante pensar sobre o que são, suas funções, finalidade, para inseri-los na prática pedagógica não como mais um recurso, mas para a promoção da aprendizagem discente imbuída de significado concreto, de autonomia e reconhecimento deste, enquanto sujeito da produção do espaço no qual se inserem.

Como bem coloca Martinelli (2011), desde a instituição da Geografia como disciplina, no início do século XIX, o atlas ganha credibilidade enquanto um tipo de livro escolar. Empreendamos então, uma distinção dos materiais didáticos proposta por Choppin (apud ROJO, 2005, p. 4-5), organizada de acordo com sua função no processo de ensino-aprendizagem:

1. Os manuais ou livros didáticos, obras produzidas com o objetivo de auxiliar no ensino de uma deter- 
minada disciplina;

2. Os livros paradidáticos ou paraescolares, obras complementares com conteúdos específicos do currículo de uma disciplina;

3. Os livros de referência, como dicionários, atlas e gramáticas, destinados a servir de apoio aos aprendizados, ao longo da escolarização;

4. As edições escolares de clássicos, que reúnem, de modo integral ou sob a forma de excertos as edições de obras clássicas.

Observemos que o atlas é compreendido como um livro de referência, servindo, basicamente, como um instrumento de apoio e contendo abordagens gerais. Mas, considerando que o ensino formal está ancorado por proposta curricular nacionalmente integrada com a disposição de conteúdos mínimos referenciados em livros didáticos, os atlas escolares municipais podem trazer conteúdos específicos, complementando e oferecendo possibilidades de inovação nas práticas pedagógicas, transcendendo tal atribuiç̧ão. $\mathrm{O}$ inovador dependerá da concepção teórico-metodológica do professor, o qual poderá partir da categoria lugar para explorar os elementos, as relações e interelações do local, o que consideramos ideal, ao se beneficiar dos conhecimentos pré-elaborados pelos alunos, para posterior geografização dos mesmos.

Debruçando-nos sobre o que se compreende por um atlas, o Instituto Brasileiro de Geografia e Estatística IBGE (2013), o define, inicialmente, como um conjunto de mapas ou cartas geográficas, o que restringe sua concepção aos produtos cartográficos. No entanto, logo em seguida, o traz para outro campo de abrangência, o de dados sistematicamente organizados, voltado para um assunto, do qual o usuário irá extrair informação. Embora, acreditemos que também a informação o integra, quando os dados são interpretados, acompanhados de textos explicativos e/ou analíticos.

Nesse sentido, França Junior e Zucchi (2013), destacam que os atlas sofreram, ao longo do tempo, intenso processo de evolução. Da visão tradicional de coleção de mapas tornaram-se complexos, apresentam informações concisas, "ferramentas" que comunicam, com imagens, gráficos, tabelas, croquis entre outras, o que auxilia na leitura do espaço geográfico.

Além dos seus elementos, precisamos observar que ao inserirmos o qualitativo escolar, o atlas se redimensiona, pois passa a ter um objetivo específico, o de cumprir o papel de recurso didático. E ao denominá-lo atlas escolar municipal o seu foco ganha delimitação espacial, a apropriação do lugar para as representações gráficas e textuais passa a ser sua espinha dorsal. Aqui uma requalificação se faz necessária, movendo novos/velhos saberes naqueles que o produz e o utiliza.

Segundo Oliveira Jr. (2011), o atlas municipal escolar busca "entendimento mais aprofundado do lugar onde se vive [...] promover passagens facilitadas entre os saberes da experiência espacial cotidiana [...] e outros saberes acerca deste lugar produzidos a partir de outras práticas sociais e discursivas" (p.16, grifo do autor). Mesclam-se a cultura, a história, a arte, a política, a economia, e tantas outras dimensões envolvidas na leitura de mundo e sua compressão, as quais ganharão materialidade a ser explorada e enriquecida com a subjetividade dos olhares.

Dentro do exposto, consideramos adequado categorizar, a grosso modo, o atlas em três grandes eixos: produções gerais, produções escolares e produções escolares locais. Enquanto produções gerais, a principal característica é o descompromisso com seu uso pedagógico e, usualmente, apresentação de dados em escala pequena ou mesmo média. As produções escolares visam um público alvo e o ensino como finalidade específica, o que se reflete na adequação das linguagens e conteúdos, contudo seus dados e informações conservam o caráter generalizador.

Os atlas escolares municipais conservam o público, a finalidade, o cuidado com a linguagem e conteúdo, entretanto sua característica primordial é a exploração do espaço vivido, as representações de dados e informações em grande escala e de modo especial, o seu processo de produção. A elaboração de um atlas escolar municipal, certamente, será direcionada por várias mãos e níveis de profissionalização. De aprendizes a doutores. De moradores a sistemáticos observadores. Dos modelos à inventividade, com crítica e reflexão. Expressará conhecimento acadêmico, mas também trará as miradas do cotidiano. De tal modo, trata-se não só de diferenciá-lo em relação a outros materiais didáticos, mas também distingui-los entre si, o que propomos com base nestas três categorias: ensino, escala e práxis.

A junção entre teoria e prática é palco para a realização do atlas escolar. Essa unidade, além de possibilitar o desenvolvimento e aprofundamento dos conceitos próprios da ciência geográfica, imbuídos de maior significado, deita-se sobre o fazer, sobre o fitar e inspecionar a realidade concreta. Poderá de tal modo, despertar sentimento de pertencimento ao lugar, de integração no processo histórico-cultural da produção do espaço, na formação da cidadania.

\section{O ENSINO DA GEOGRAFIA ESCOLAR E O ESPAÇO GEOGRÁFICO PRÓXIMO}

Qual a importância da inserção do lugar nas aulas de 
Geografia? De trabalhar material didático que contém paisagens, dados e informações conhecidas e vivenciadas? De superar o conceito de lugar apenas relacionado à localização no espaço, como tem sido compreendido e associado ao longo do tempo?

Partindo da Geografia, compreendemos que esta área do conhecimento oferece base essencial para a compreensão e intervenção na realidade social. O estudo das relações sociedade e natureza, no espaço e no tempo, é objetivo da Geografia, e sua leitura se realiza por meio das categorias espaço, lugar, território, região, redes e paisagem. Esta área do conhecimento propõe um fazer pedagógico que tenha como finalidade ampliar a capacidade dos alunos do ensino fundamental de observar, conhecer, explicar, comparar e representar as características de diferentes paisagens e espaços geográficos, iniciando do lugar em que vivem (BRASIL, 1998).

A partir de estudos mais recentes, o conceito de lugar ganhou novas dimensões. Tuan (1979, apud NASCIMENTO, 2012, p. 27) afirma que "o lugar não é só um fato a ser explicado na ampla estrutura do espaço, ele é a realidade a ser esclarecida e compreendida sob a perspectiva das pessoas que lhe dão significado". O lugar se apresenta assim, como o espaço vivido, com suas especificidades, a partir das relações sociais, da criação de laços afetivos e da identidade dos sujeitos nele inseridos. Espaço esse dotado de pertencimentos e objetos empiricamente observáveis, os quais revelam as interfaces da relação sociedade-natureza, sujeito-lugar. Esta orientação encontra-se inserida nos próprios Parâmetros Curriculares Nacionais - PCNs, ao afirmar que:

O lugar é onde estão as referências pessoais e o sistema de valores que direcionam as diferentes formas de perceber e constituir a paisagem e o espaço geográfico. É por intermédio dos lugares que se dá a comunicação entre homem e mundo (BRASIL, 2008, p. 29).

Compreendo que o lugar é contenedor da história dos sujeitos que o produz e nele vivem (CALLAI, 2005, p. 236), o entende como um "livro" aberto para o aprendizado geográfico. O espaço escolar, enquanto responsável pela promoção dessa leitura, ao aproximar o sujeito do seu espaço de vivência contribui para que, ao compreender relações sociais a ele inerentes, este se reconheça participante do processo histórico-espacial de sua produção, e seja capaz de analisar, questionar e intervir sobre sua realidade social.

Nesse sentido, a inserção dos aspectos locais nas abordagens dos conteúdos é de extrema importância, pois é possível fazer a contextualização, relacionando-os com as realidades vivenciadas pelos estudantes, levando em consideração seus conhecimentos prévios e suas experiências, a fim de que os mesmos possam compartilhar suas ideias e associar seus conhecimentos empíricos com os saberes científicos trazidos pelo professor

De acordo com Santos (2007/2008, p. 99), "ao fazer a leitura do lugar conhecido, desencadeia-se o processo de compreensão da realidade no dia a dia pela criança". Dessa forma, o estudante poderá construir seus próprios conhecimentos a partir de realidades vivenciadas, afastando-se da aprendizagem mecânica, memorizada, vazia de significado, que coloca o aluno como espectador dos processos, não como sujeito. Compreende-se, dessa maneira, que o atlas escolar municipal pode figurar como uma metodologia inovadora de aprendizagem.

Sobre sua elaboração, Martinelli (2008, p.23), esclarece não ser simples, destacando que "não basta simplificar mapas, nem torná-los mais atraentes, muito menos selecionar os temas mais fáceis," visto que a orientação e localização no espaço são potencializadas pela cartografia. Além disso, a elaboração de um atlas que tenha como enfoque o lugar de vivência proporciona a disposição de um material didático capaz de aproximar professores e alunos da leitura de mundo.

É nesse intento que nos colocamos como desbravadores-aventureiros dos lugares inseridos no semiárido baiano, na intenção de aproximar professor e aluno da leitura geográfica do seu espaço próximo, potencializando a formação criativa, significativa, crítica e socialmente participativa.

\section{ELABORANDO MATERIAL DIDÁTICO LO- CAL: O ATLAS ESCOLAR DO MUNICÍPO DE SERRINHA, NA BAHIA}

Este é um relato de experiência, decorrente das atividades desenvolvidas no projeto "Laboratório SIG: atlas escolar", no curso de Licenciatura em Geografia da Universidade do Estado da Bahia, Campus XI, Serrinha. Como ocorre no âmbito do ensino superior, além da produção do material com destino escolar final, possibilitando acesso sistematizado aos dados e informações locais/regionais de temas variados para o público do ensino básico, também traçou-se como objetivos específicos, desenvolver habilidades na elaboração e desenvolvimento de projetos, enfatizar o potencial da aplicação das tecnologias informacionais na produção de material didático e ensino da Geografia, vinculando-se, assim, diretamente ao processo formativo do professor.

\subsection{Como foi feito?}

Para a execução deste projeto de extensão universitária, iniciado em 2012, partimos de um intuito maior, voltado para o aprender, o pesquisar, o fazer pedagógico em curso de licenciatura e a utilização das tecnologias geográficas e demais ferramentas computacionais visando a produção de material 
didático para a confecção de um recurso com conteúdo local destinado ao trabalho nas escolas do Território de Identidade do Sisal, as quais historicamente ficaram às margens das abordagens ou estas se fazem a partir da leitura do outro. Para tanto, formou-se um grupo com dois professores universitários de Geografia e quatro monitores graduandos de licenciatura em Geografia.

Inexperientes na elaboração de material didático e atlas escolares municipais, diversos desafios foram sendo colocados nesse percurso, mas muitas conquistas foram obtidas. Este foi um processo de ensino-aprendizagem para professores e discentes, do qual tratamos a seguir.

A primeira grande pergunta foi: De onde partir? E em seguida: Onde queremos chegar? E, não diferente de qualquer execução de projeto nos debruçamos inicialmente sobre a revisão de literatura depois de identificarmos quatro temas âncora para sua realização, quantitativamente definidos em função do número de monitores: (a) A categoria lugar e o ensino de Geografia; (b) Material didático com enfoque em atlas escolares e o ensino de Geografia; (c) As novas tecnologias e suas potencialidades para o ensino de Geografia; (d) A Cartografia Escolar e o ensino de Geografia.

Textos foram selecionados, lidos e discutidos em grupo, assim como atlas foram analisados. Momento de maturação, hoje reconhecido como essencial para firmar as bases teóricas, o entendimento e compromisso com o propósito final do projeto. Firmou-se a concepção de atlas escolar que se desejava. Certamente, não mais um material didático ou de apoio pedagógico, mas um referencial metodológico inovador, do qual o professor possa partir mobilizando os conhecimentos prévios dos alunos, apurar a leitura geográfica dos aspectos antes vistos, mas agora compreendidos à luz da análise geoespacial e suas conduções relacionais.

Um atlas escolar municipal contendo elementos gráficos, a exemplo dos mapas, fotografias, gráficos estatísticos e elementos textuais, capazes de contextualizar o "próximo" nas distantes teorias. Trazendo o cotidiano para a sala de aula em uma linguagem clara, objetiva, mas rica de significados, de sensações, de detalhes. Abrindo portas para que o professor possa explorar o cotidiano relacionando-o aos objetivos da Geografia Escolar, pois, é bom que se tenha claro, o atlas não faz o trabalho sozinho: a ferramenta precisa das mãos do ferreiro para transformar o aço em obra de arte.

Terminada a fase de reconhecimento do 'terreno' a ser explorado, da definição do norte a ser atingido, pensamos na diagramação. Surpreende perceber como o espaço escolar cerceia o que temos de mais espontâneo: a criatividade. Estamos engessados pelos modelos, pela insegurança advinda do apontamento do erro e, no momento de pensar livremente o que queremos, o como queremos, nos anulamos na espera pelo outro. Este foi um exercício de difícil resultado, pois li- bertar-se das ataduras da educação tradicional é um processo que requer tempo e re-aprendizado.

Chegamos a pensar em terceirizar a diagramação. Mas, por dificuldades de execução financeira decidimos organizar nós mesmos a apresentação do atlas. Decisão acertada, pois libertamos a criatividade, propondo páginas sem modelos de distribuição de elementos gráficos e textuais pré-elaborados, sem rigor de forma.

Firmada a concepção e estrutura, seguimos para os conteúdos e escolha do município. O que deve conter? Terceira pergunta que foi respondida à luz das orientações nacionais para o ensino. Não é possível ignorar o como a escola básica organiza suas atividades, já que elas serão o público alvo. Seus conteúdos encontram-se referenciados nos Parâmetros Curriculares Nacionais - PCNs.

Nestes, os conteúdos estão vinculados aos ciclos de ensino, sendo prerrogativa básica esse direcionamento, destacando-se que não entraremos aqui em discussões políticas e ideológicas quanto a estas diretrizes, pois não foi este o nosso objetivo. E, considerando que os licenciados em Geografia, normalmente, atuarão a partir do terceiro ciclo do ensino fundamental, este foi escolhido para a elaboração do atlas escolar tendo o município de Serrinha como foco, em função de sediar o campus de nossa atuação. Assim, com base nos conteúdos para o terceiro ciclo do ensino fundamental, traçamos um esboço do conteúdo do atlas (Quadro 1), destacando que o mesmo não segue ordem idêntica ao apresentado no PCN de Geografia:

Quadro 1 - Esboço da organização/conteúdos do atlas escolar municipal.

\begin{tabular}{|c|c|}
\hline EIXOS & CONTEÚDOS \\
\hline $\begin{array}{c}\text { A cartografia como } \\
\text { instrumento na } \\
\text { aproximação dos lugares e } \\
\text { do mundo }\end{array}$ & $\begin{array}{l}\text { - APRENDO A LER, QUERO FALAR } \\
\text { (ensinando a ler e fazer fotografias, tabelas, } \\
\text { gráficos e mapas) }\end{array}$ \\
\hline $\begin{array}{l}\text { A Geografia como uma } \\
\text { possibilidade de leitura e } \\
\text { compreensão do mundo }\end{array}$ & $\begin{array}{l}\text { - ONDE ESTÁ O MEU LUGAR NO PLANETA } \\
\text { TERRA? (Localização do município) } \\
\text { - QUAL É A "MINHA" HISTÓRIA (história do } \\
\text { municipio, transformaçōes do espaço } \\
\text { geográfico, diferenciação do espaço } \\
\text { geográfico-urbano e rural) }\end{array}$ \\
\hline $\begin{array}{l}\text { O estudo da natureza e sua } \\
\text { importância para o homem }\end{array}$ & $\begin{array}{l}\text { - A FORMA ONDE PISO (relevo, solo, } \\
\text { desertificaçăo, erosão do solo) } \\
\text { - QUENTE E SECO: CONHEÇO BEM } \\
\text { (Recursos hídricos e clima) } \\
\text { - MINHA CAATINGA VERDE-CINZA } \\
\text { (Definiçăo, distribuição e caracteristicas) } \\
\text { - TAMBEM SOU NATUREZA } \\
\text { (desmatamento, lixōes, ocupaçōes } \\
\text { irregulares, pobreza, degradação dos } \\
\text { recursos hidricos e diversos ambientes, } \\
\text { consequências do uso e ocupaçăo da terra) }\end{array}$ \\
\hline $\begin{array}{l}\text { O campo e a cidade como } \\
\text { formaçōes socioespaciais }\end{array}$ & $\begin{array}{l}\text { - EOTEMPO NÅO PASSA? (Acumulaçăo do } \\
\text { tempo no espaço: as feiras livres, as } \\
\text { rugosidades espaciais, latifúndio e } \\
\text { pequenas propriedades, comércio e } \\
\text { indústria). }\end{array}$ \\
\hline
\end{tabular}


A compilação e elaboração de dados primários para contemplar os conteúdos foi o próximo passo. Esta é uma das maiores dificuldades enfrentadas por aqueles que se propõem trabalhar em grandes escalas. Para o município de Serrinha, os mapeamentos realizados sobre os temas físicos da geografia encontram-se em pequenas escalas. Assim, para abordarmos a geomorfologia, a geologia, a pedologia os dados disponíveis são muito generalizados.

Para atender nossa demanda, as fontes de dados foram as mais variadas possíveis: censo demográfico do IBGE (2010), arquivos vetoriais do Sistema de Informações Geográficas do Estado da Bahia (BAHIA, 2005), dados e informações do Ministério do Meio Ambiente (BRASIL, 2004) e do Instituto Nacional de Meteorologia (BRASIL, 2016), campo para registro fotográfico, uso de técnicas de geoprocessamento para extração de informações de imagens obtidas por sensoriamento remoto sobre relevo, hidrografia e temas diversos, além da elaboração de gráficos e mapas em ambiente de Sistema de Informação Geográfica - SIG.

A realização de curso específico para elaboração de mapas temático em SIG, bem como orientações para organização e tratamento de dados alfanuméricos, com geração de gráficos e tabelas foi imprescindível. Constatamos a fragilidade no uso das ferramentas geográficas e no conhecimento básico no uso de planilhas. Este é um aspecto limitante, pois exige conhecimento técnico, o qual entendemos também ser necessário ao professor, pois possibilita e amplia seu universo de atuação.

Infelizmente, o fazer, não raras vezes é secundarizado e criticado na academia. Mas, a transposição didática vai além de uma bela bagagem teórica. Teoria e prática se complementam, rompem fronteiras do conteúdo distante, aproximam aluno e professor da produção do conhecimento, a qual não se dá só no campo das ideias. Retomando as orientações do PCN de Geografia, dois objetivos podem ser destacados nesta perspectiva (BRASIL, 1998):

Utilizar diferentes linguagens - verbal, musical, matemática, gráfica, plástica e corporal - como meio para produzir, expressar e comunicar suas ideias, interpretar e usufruir das produções culturais, em contextos públicos e privados, atendendo a diferentes intenções e situações de comunicação; Saber utilizar diferentes fontes de informação e recursos tecnológicos para adquirir e construir conhecimento. (1998, p. 6-7).

Entendemos que a falta do conhecimento prático para a elaboração dos produtos cartográficos pode figurar como inibidora de propostas semelhantes, que visem evidenciar dados e informações locais, embora, haja um grande arsenal de materiais e programas de livre acesso. Então, como pedir ao professor que dê aquilo que não possui? A formação continuada, com devido diagnóstico das fragilidades forma- tivas, das demandas em sala de aula, dos novos recursos disponíveis, das exigências contemporâneas de interdisciplinaridade e formação de protagonistas da produção social do espaço, a atenção nas academias a estas necessidades, faria total diferença na qualidade do ensino na escola básica.

Com a realização dos cursos demandados pelo projeto, bem como orientações intensivas, foram elaborados elementos gráficos e registros fotográficos para o atlas escolar municipal de Serrinha-BA. O próximo desafio, ainda em curso é a finalização desses elementos e a produção dos textos que acompanharão as imagens, que lhes darão suporte geográfico teórico, apresentando ao estudante o que já conhecem sob nova perspectiva, a do saber sistematizado.

Com certeza, não menor do que o passado, este desafio recai na fragilidade teórica, interpretativa, relacional, de origem não apenas acadêmica, mas fundada em todo o percurso formativo, visto que as 'receitas' sempre foram dadas e agora é hora de criar, de construir o novo, de se expor enquanto produtor de conhecimento, posição nada familiar.

\subsection{Até onde chegamos?}

Todo planejamento é flexível. Nem tudo que é proposto é possível de ser executado. E são vários os fatores intervenientes: limitações com recursos financeiros, com dados, com formação, com o tempo de execução, com descontinuidade nos trabalhos por mudança nos componentes do grupo. Este último aspecto, atravessaremos na próxima etapa. Formandos saem e novos monitores ingressam e, com eles, a necessidade de reconstrução para ambientação no processo, pois caso contrário se faz produção em série, se perde a noção de complexidade do todo e o resultado conterá tal fragmentação.

No entanto, o lugar no qual chegamos já nos deixa satisfeitos, por termos mobilizado conhecimento, proporcionado crescimento acadêmico, preocupação com a prática docente que visualiza o aluno como sujeito no processo, despertado para as possibilidades criativas e inovadoras no campo da Geografia Escolar. Não podemos nos frustrar ao não alcançarmos o ideal, o ideal não é para ser alcançado, é para ser perseguido. É como a esperança, pois sem ela perde-se o interesse pela busca, já nos diz Freire (1997), pelos outros e por si mesmo. A incompletude gera a necessidade de continuar e o fazer inicial despertará outros fazeres.

O Quadro 2 apresenta os produtos gráficos possíveis de serem realizados a partir da proposta inicial, depois do levantamento de dados, bem como o status de execução destes.

Para exemplificar, foram selecionados três produtos elaborados em nosso projeto, referentes aos eixos "O estudo 
da natureza e sua importância para o homem" e "O campo e a cidade como formações socioespaciais". A figura 1 aborda aspectos relacionados ao esgotamento sanitário no município de Serrinha, enquanto que a figura 2 trata do processo da desertificação e a figura 3 apresenta aspectos das heranças locais vinculadas à formação do espaço brasileiro. Para tanto, destacamos o uso de três recursos gráficos diferentes: o gráfico, o mapa e a fotografia.

Quadro 2 - Plano de trabalho em execução

\begin{tabular}{|c|c|}
\hline EIXOS & PRODUTOS GRÁFICOS \\
\hline $\begin{array}{l}\text { A cartografia como } \\
\text { instrumento na } \\
\text { aproximação dos lugares e } \\
\text { do mundo }\end{array}$ & Em andamento \\
\hline $\begin{array}{l}\text { A Geografia como uma } \\
\text { possibilidade de leitura e } \\
\text { compreensão do mundo }\end{array}$ & $\begin{array}{l}\text { Mapas iniciais de localização (em andamento) } \\
\text { Mapa da zona urbana e rural } \\
\text { Gráfico da população total } \\
\text { Gráfico da população urbana e rural } \\
\text { Mapa de densidade demográfica } \\
\text { Dados sobre expectativa de vida, mortalidade } \\
\text { infantil } \\
\text { Gráfico de gênero } \\
\text { Gráfico de raça } \\
\text { Fotos sobre manifestações culturais e históricas }\end{array}$ \\
\hline $\begin{array}{l}\text { O estudo da natureza e sua } \\
\text { importância para o homem }\end{array}$ & $\begin{array}{l}\text { Gráfico de temperatura } \\
\text { Gráfico de pluviosidade } \\
\text { Previsão do tempo } \\
\text { Foto da estação meteorológica de Serrinha } \\
\text { Fotos de captação, armazenamento e usos da } \\
\text { água } \\
\text { Mapa dos tipos de abastecimento de água } \\
\text { Mapa dos tipos de disposição de lixo } \\
\text { Gráfico dos tipos de esgotamento sanitário } \\
\text { Fotos de degradaçăo ambiental } \\
\text { Mapa de desertificação } \\
\text { Atividades econômicas } \\
\text { Etapas em andamento: } \\
\text { Perfil topográfico } \\
\text { Altitude } \\
\text { Superfície 3D } \\
\text { Declividade } \\
\text { Fotos de caracteristicas pedológicas } \\
\text { Mapa hidrográfico } \\
\text { Fotos da cobertura vegetal }\end{array}$ \\
\hline $\begin{array}{l}\text { O campo e a cidade como } \\
\text { formações socioespaciais }\end{array}$ & $\begin{array}{l}\text { Registros fotográficos das feiras livres (compilado) } \\
\text { Gráficos sobre produçăo e circulação de } \\
\text { mercadorias (compilado) } \\
\text { Fotos dos monumentos históricos municipais }\end{array}$ \\
\hline
\end{tabular}

É importante frisar que não se tem o objetivo de esgotar o conteúdo, mas abrir possibilidades de diálogo e investigação. No primeiro exemplo (Figura 1), deixa-se espaço para explorar, dentre outros, o que é o esgotamento sanitário; o levantamento e a análise de dados sobre esgotamento sanitário, nas diferentes escalas geográficas (global, nacional, regional e local); os aspectos sociais vinculados aos serviços de saneamento básico; as consequências da falta de esgotamento sanitário; os tipos de esgotamento sanitário e como o município gerencia esta questão; responsabilidade do indivíduo e da sociedade mediante o destino e tratamento dos efluentes domésticos.

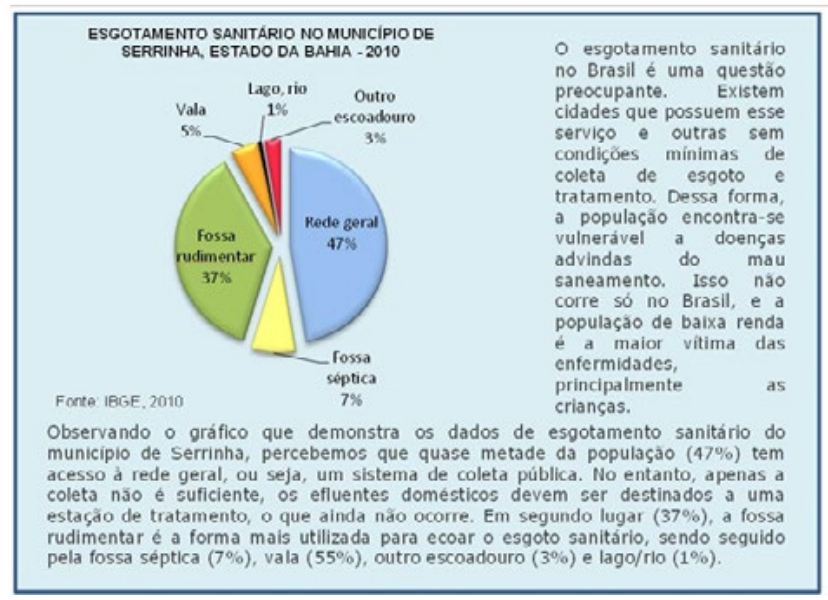

Figura 1 - Esgotamento sanitário no município de Serrinha, estado da Bahia.

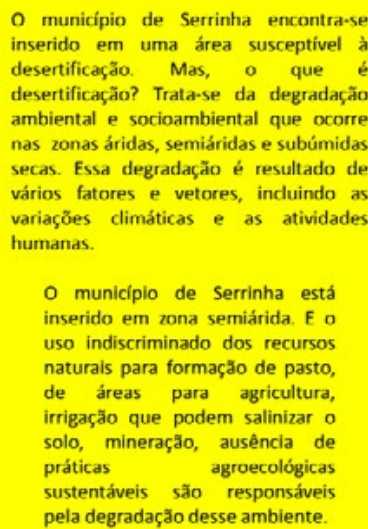

- municiplo de Serrinha está inserido em zona semiárida. $\mathrm{E}$ o uso indiscriminado dos recursos naturais para formaçăo de pasto, de áreas para agricultura, irrigação que podem salinizar o solo, mineraçăo, ausência de práticas agroecológicas sustentáveis são responsáveis pela degradação desse ambiente.

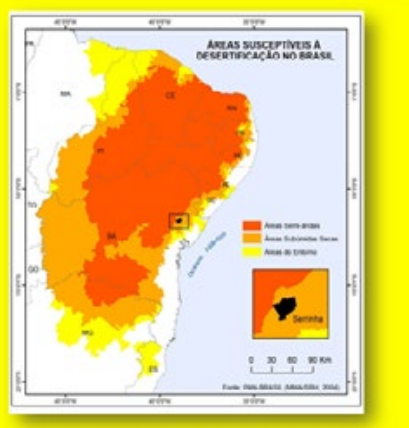

Prevenir, reabilitar a recuperar as terras degradadas é o meio de se combater a desertificaçăo. Esse é o papel dos gestores, da sociedade, de todos nós.
Figura 2-Desertificação e o município de Serrinha, no estado da Bahia

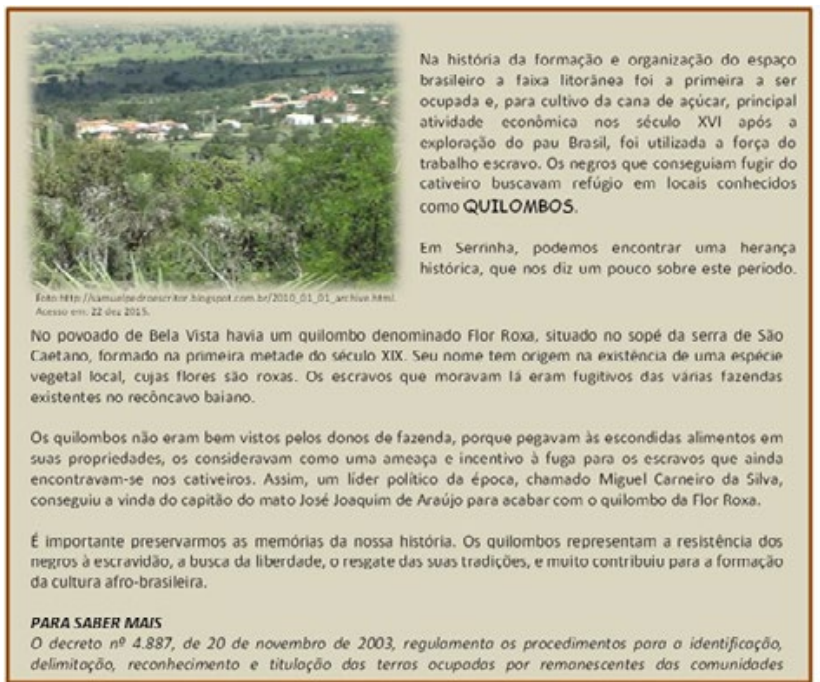

Figura 3 - O povoado de Bela Vista em Serrinha, estado da Bahia Fonte: Baseado em Franco (1996); Campos (1998) e Pedro (2009) 
Na segunda proposta (Figura 2), é possível aprofundar os aspectos conceituais a respeito da desertificação, suas causas, consequências e quais medidas podem ser tomadas para evitar/combater esse processo. Conduz a uma necessária compreensão sobre o tipo climático local e suas especificidades; o uso dos recursos naturais, destacando as atividades econômicas e seus impactos; a interação da sociedade com a natureza, enfatizando o manejo do solo, o uso da água, o desmatamento; e a reflexão sobre atitudes sustentáveis.

Quanto a última proposta apresentada (Figura 3), deixa-se em evidência a formação socioespacial do município relacionada com a brasileira, buscando-se despertar no estudante a memória histórica e cultural. Pode-se realizar um trabalho de pesquisa sobre a história da ocupação, o patrimônio cultural e arquitetônico (rugosidades espaciais), junto aos estudantes, analisando seus aspectos históricos e o rebatimento destes elementos na configuração atual do município. Cabe destacar que todo o seu conteúdo foi extraído de fontes secundárias, tendo em vista que essa estratégia é normalmente requerida ao se trabalhar com dados locais, em função da escassez de tempo, de recursos financeiros e de pessoal para realização do levantamento primário.

\section{CONSIDERAÇÕES FINAIS}

O projeto teve como meta a elaboração de atlas para todos os municípios do Território de Identidade do Sisal, do qual a UNEB é integrante. Por enquanto, nessa primeira experiência com o município de Serrinha, assim considerada por oferecer o desafio inicial e apresentar as fragilidades e avanços no processo, vamos desnudando o que deve ser evitado, modificado, repensado e registrando o que deve ser mantido para os demais atlas a serem elaborados.

Tomando-o como projeto piloto, dar-se-á continuidade para que os produtos gráficos e fotográficos sejam finalizados, assim como a produção textual seja realizada e concluída. A disposição desses elementos no papel já começa a ser executada, mostrando ser possível gerar um produto visual com qualidade, mesmo diante da inexperiência da equipe executora: contamos principalmente com a criatividade $\mathrm{e}$ bom senso.

Depois de concluído os trabalhos, o atlas será encaminhado para a publicação e uma nova etapa será iniciada com o seu recebimento. As escolas públicas municipais deverão ser chamadas para tomar conhecimento do material produzido, realizando-se oficinas com os professores da educação básica, no intento de auxiliá-los no seu uso didático.

Podemos pensar em ampliar o grupo de trabalho de elaboração do próximo atlas, integrando professores da educação básica no processo. É o que consideramos ideal, pois atuaremos na formação continuada desses profissionais, possibilitando inclusive que, em sala de aula, outros materiais sejam construídos com a contribuição dos seus alunos, indo assim, além do receber o material didático, promovendo saberes.

Da experiência atual fica a certeza da fertilidade do nosso campo educativo. Os graduandos estão ávidos por saberes que oriente a sua prática docente. Esta é uma constatação cotidiana: abrindo-se espaço, a construção do conhecimento acontece e com ela a emancipação do sujeito.

\section{REFERÊNCIAS}

BAHIA, Secretaria Estadual de Recursos Hídricos. Plano Estadual de Recursos Hídricos - SIG. Salvador: SRH, 2005.

BRASIL, Instituto Nacional de Meteorologia. Estações e Dados. Disponível em: < http://www.inmet.gov.br/ portal/index.php?r=bdmep/bdmep $>$. Acesso em: 09 mai 2016.

BRASIL, Ministério da Educação. Parâmetros Curriculares Nacionais: geografia. Brasília, MEC/SEF, 1998.

BRASIL, Ministério do Meio Ambiente. Dados Georrefereciados. Disponível em: $<$ http://www.mma.gov.br/ areas-protegidas/cadastro-nacional-de-ucs/dados-georreferenciados >. Acesso em: 17 mar 2014.

CALLAI, H. C. "Aprendendo a ler o mundo: a geografia nos anos iniciais do ensino fundamental". Cad. Cedes, vol. 25, n. 66 - p. 227-247, maio/ago. 2005.

\section{CAMPOS, M. F. H. Conhecendo Serrinha: história e geografia. Feira de Santana: UEFS, 1998.}

CASTELLAR, S. V. "A cartografia e a construção do conhecimento em contexto escolar". In: ALMEIDA, R. D. (Org.). Novos rumos da cartografia escolar: currículo, linguagem e tecnologia. São Paulo: Contexto, 2011. p.121. 135 .

FRANÇA JUNIOR, P.; ZUCCHI, V. P. "Atlas municipal de Cambira/PR: construindo conhecimentos geográficos". Geografia Ensino \& Pesquisa, v. 17, n.1 - p. 161-171, jan./abr. 2013. 
FRANCO, T. Serrinha: a colonização portuguesa numa cidade do sertão da Bahia. Salvador: EGBA, Assembleia Legislativa do Estado da Bahia, 1996.

FREIRE, P. "A Educação e o Processo de Mudança Social". In.: Educação e Mudança. RJ: Paz e

Terra, 1997.

GONÇALVES, A. R. "Atlas Municipais Escolares: entre os mapas dos vencedores e das rupturas". In: VI COLÓQUIO DE CARTOGRAFIA PARA CRIANÇAS E ESCOLARES E II FÓRUM LATINOMAERICANO DE CARTOGRAFIA PARA ESCOLARES, 2009. Juiz de Fora. Anais... Disponível em: http://cartografiaescolar. blogspot.com.br/2009/08/vi-coloquio-de-cartografia-para.html. Acesso em: 08 dez. 2015.

IBGE. Atlas Escolar. Disponível em: < http:/ /atlasescolar.ibge.gov.br/conceitos-gerais/o-que-e-um-atlas-geografico.html>. Acesso em: 03 set 2013.

IBGE. Censo Demográfico 2010. Disponível em: < http://downloads.ibge.gov.br/ downloads_ estatisticas. htm>. Acesso em: 09 abr 2013.

MARTINELLI, M. "Um atlas geográfico escolar para o ensino-aprendizagem da realidade natural e social". Portal da Cartografia, v.1, n.1 - p. 21-34, maio/ago. 2008.

MARTINELLI, M. "Atlas Geográfico para Escolares: uma revisão metodológica”. In: AMEIDA, R. D. (Org.) Novos Rumos da Cartografia Escolar: currículo, linguagem e tecnologia. São Paulo: Contexto, 2011. p. 13 . 35.

NASCIMENTO, L. K. O lugar do Lugar no ensino da Geografia: Um estudo das escolas públicas do Vale da Ribeira-SP. 2012. Tese (Doutorado em Geografia) - Programa de Pós-Graduação em Geografia Física, USP, São Paulo-SP.

OLIVEIRA JR., W. "Fotografias e conhecimentos do lugar onde se vive: linguagem fotográfica e atlas municipais escolares". In: AMEIDA, R. D. (Org.) Novos rumos da cartografia escolar: currículo, linguagem e tecnologia. São Paulo: Contexto, 2011. p. 13 . 35.

PEDRO, S. Remanescência Quilombola: A flor roxa que não tombou. Disponível em: $<$ http://samuelpedroescritor.blogspot.com.br/2010/01/ remanescencia-qui- lombola-flor-roxa-que.html>. Acesso em 22 dez 2015.

ROJO, R. "Materiais Didáticos: escolha e uso". In: BRASIL. Ministério da Educação. Materiais Didáticos: escolha e uso. Boletim 14, ago. 2005.

SANTOS, J.J. "Ensino de Geografia nos anos iniciais: leitura de mundo através de conceitos e mapas". Poiésis Pedagógicas, v.5/6 - p. 95-112, jan./dez. 2007/2008.

SANTOS, M. Metamorfoses do espaço habitado. São Paulo: HUCITEC, 1997.

SOUZA, C. S.; IGLESIAS, A. G.; PAZIN-FILHO, A. “Estratégias inovadoras para métodos de ensino tradicionais: aspectos gerais". Revista Medicina, v. 47, n. 3 - p. 284-292, jul. 2014.

\section{Correspondência das autoras:}

Ana Isabel Leite Oliveira

e-mail: isanaleite@hotmail.com

Eliany Dionizio Lima

e-mail: lialima_1981@hotmail.com

Karla Maria de Queiroz. dos Santos

e-mail:kmsantos@hotmail.com

\section{Rute Araújo da Silva}

e-mail: rutedevalente@hotmail.com

Artigo recebido em: 02/08/2016

Revisado pelo autor em: 16/02/2017

Aceito para publicação em: 10/04/2017 